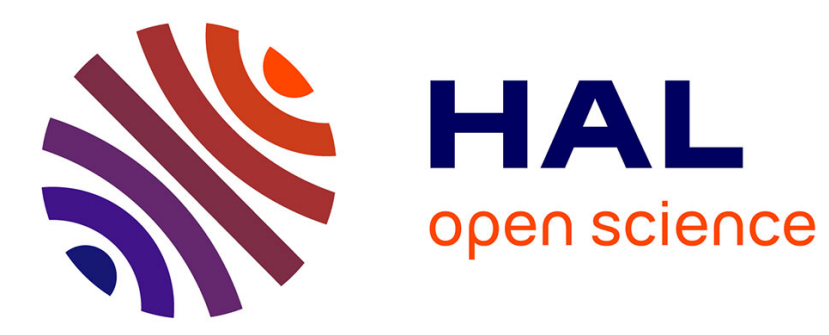

\title{
LPV-based MR damper modelling
}

\author{
V.A. Diaz-Salas, R. Morales-Menendez, R.A Ramirez-Mendoza, Olivier \\ Sename, Luc Dugard
}

\section{To cite this version:}

V.A. Diaz-Salas, R. Morales-Menendez, R.A Ramirez-Mendoza, Olivier Sename, Luc Dugard. LPVbased MR damper modelling. MED 2011 - 19th Mediterranean Conference on Control and Automation, Jun 2011, Corfou, Greece. pp.201-206, 10.1109/MED.2011.5982976 hal-00682121

\section{HAL Id: hal-00682121 \\ https://hal.science/hal-00682121}

Submitted on 23 Mar 2012

HAL is a multi-disciplinary open access archive for the deposit and dissemination of scientific research documents, whether they are published or not. The documents may come from teaching and research institutions in France or abroad, or from public or private research centers.
L'archive ouverte pluridisciplinaire HAL, est destinée au dépôt et à la diffusion de documents scientifiques de niveau recherche, publiés ou non, émanant des établissements d'enseignement et de recherche français ou étrangers, des laboratoires publics ou privés. 


\title{
LPV-based MR Damper Modelling
}

\author{
Vicente A. Diaz-Salas, Ruben Morales-Menendez, Ricardo Ramírez-Mendoza \\ Olivier Sename, Luc Dugard
}

\begin{abstract}
An MR damper is a device that exhibits a high nonlinear and complex behavior with a hysteresis phenomenon. A comparison between different state-of-the-art and a Linear Parameter Varying (LPV) models for Magneto-Rheological (MR) dampers is presented. Several experimental datasets validate that Linear Parameter Varying (LPV)-based model outperforms the classical MR damper models for $51 \%$ than any structures considering the Error to Signal Ratio index and $37 \%$ better considering the Squared root of Sum of Squared Errors index.
\end{abstract}

\section{INTRODUCTION}

$M R$ dampers represent an improvement in the field of intelligent suspensions. This type of devices generate a mechanical impedance to velocity with a variable damping factor by using intelligent materials: Magneto-Rheological fluid. However, this type of damper shows a highly non-linear behavior when applying different damping ratios (controlled by the electric current input), see Figure 1.

Several research works has been published. In [1] one of the first hysteresis model is proposed, from which several other structures have been developed [2]-[5]. The most relevant models were the Semi-Phenomenological (SP) [6], and the Phenomenological (P) [7] ones. The $P$ model exploit the phase transition theory. Also, blackbox models are referenced to describe mathematically the shock absorber behavior [2], [8].

These structures serve as a basis to replicate the MR damper behavior. However, it is important to provide a control-oriented dynamical description of this device, suitable to design control strategies to enhance comfort, steering, and road grip.

The Linear Parameter-Varying (LPV) approach allows to allocate the non-linearities of this device in the model. LPV input variable is designed to detect when the damper is exploring an hysteretic zone, and aids the model to reproduce the MR damper's complex behavior.

Section II reviews the literature of $M R$ damper models. Section III describes the proposed LPV-based model. Section IV includes the experimental setup and the Design of Experiments (DoE). Section V compares the obtained results. Finally, section VI concludes the research.

V.A. Díaz-Salas is a MSc Student at Tec de Monterrey, Monterrey, Mexico. A00790521@itesm.mx

R. Morales-Menendez and R. Ramirez are full professors at Tec de Monterrey, Monterrey, Mexico. \{rmm, ricardo.ramirez\}@itesm.mx

O. Sename and L. Dugard are full professors at INPG, Grenoble, France. \{olivier.sename, luc.dugard\}@gipsa-lab.grenoble-inp.fr

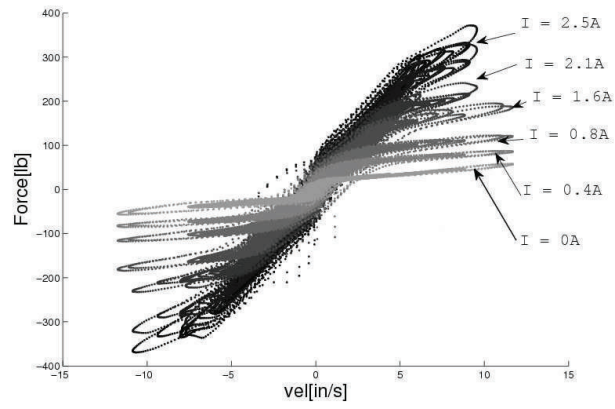

Fig. 1. Force-velocity (F-V) map of an MR damper for different electric current inputs.

\section{MR DAMPER MOdels REVIEW}

\section{A. State-of-the-art models}

Two representative models were reviewed: the Phenomenological (P) and Semi-Phenomenological (SP) structures, because they may be suitable for applications of control design [9], [10].

[6] proposes the SP structures which uses the displacement velocity of the damper to describe the hysteretic behavior.

$$
F_{m r}(t)=S_{1} \tanh \left(S_{3}\left(v(t)+\frac{V_{0}}{X_{0}} x(t)\right)\right)+S_{2}\left(v(t)+\frac{V_{0}}{X_{0}} x(t)\right)
$$

Table I describes the terminology used in this paper. This model is divided in three main components: two linear parts depending on the displacement and velocity respectively and a third part for the hysteresis phenomena. By modifying these three components, it is possible to introduce the electric current functionality.

[7] introduces a Phenomenological model. It is based on a mathematical description of the evolution of the shear stress of the material inside the MR damper (when it changes from a solid state to a semi-solid one).

A Lagrangian analysis was performed, using the constitutive mechanical relationship between the magnitudes of stress and the deformation of the material, and defining the kinetic and potential contributions for the phase transition, equation (2):

$w_{1} \ddot{F}_{m r}(t)+w_{2} \dot{F}_{m r}(t)+w_{3} F_{m r}(t)+w_{4} F_{m r}^{3}(t)+w_{5} F_{m r}^{5}(t)=v(t)$ 
TABLE I

LIST OF VARIABLES

\begin{tabular}{|c||l|c|}
\hline Variable & Description & Units \\
\hline \hline$F_{m r}(t)$ & Force generated by the MR damper. & $l b_{F}$ \\
\hline$\hat{F}(t)$ & Modeled MR damper force. & $l b_{F}$ \\
\hline $\mathrm{x}(\mathrm{t})$ & Displacement of the MR damper. & in \\
\hline $\mathrm{v}(\mathrm{t})$ & Velocity excitation applied to the MR damper. & in/sec \\
\hline $\mathrm{i}(\mathrm{t})$ & Electric current input applied to the MR damper. & Ampere \\
\hline $\mathrm{u}(\mathrm{t})$ & State space input variable & in/sec \\
\hline$S_{j}$ & SP model coefficients. & - \\
\hline$V_{0}$ & Hysteretic critical velocity in SP model. & in/sec \\
\hline$X_{0}$ & Hysteretic critical displacement in SP model. & in \\
\hline$w_{j}$ & Coefficients of Wang Phenomenological model. & - \\
\hline$\rho(t)$ & Scheduling variable of LPV system. & - \\
\hline$\rho_{\min }$ & Lower value of the scheduling parameter. & - \\
\hline$\rho_{m a x}$ & Upper value of the scheduling parameter. & - \\
\hline$\lambda$ & Number of scheduling parameters. & - \\
\hline$n_{\rho}$ & Polynomial degree of the non-linear approx. & - \\
\hline$n_{m}$ & Degree of the discrete version of the system. & - \\
\hline $\mathbf{z}(\mathrm{t})$ & State vector of state space LPV model. & - \\
\hline $\mathrm{f}(\mathrm{t})$ & Output variable of state space LPV model. & - \\
\hline $\mathrm{A}(\rho(\mathrm{t}))$ & State matrix of state space LPV model. & - \\
\hline $\mathrm{B}(\rho(\mathrm{t}))$ & Input matrix of state space LPV model. & - \\
\hline $\mathrm{C}(\rho(\mathrm{t}))$ & Output matrix of state space LPV model. & - \\
\hline $\mathrm{D}(\rho(\mathrm{t}))$ & Feedthrough matrix of state space LPV model. & - \\
\hline$\delta_{i}$ & Internal parameter integer polynomial exponent. & - \\
\hline $\mathrm{z}$ & Discrete-time operator. & - \\
\hline$M(z, \rho)$ & Model parameter-dependent denominator. & - \\
\hline$N(z, \rho)$ & Model parameter-dependent numerator. & - \\
\hline$b_{j}(\rho)$ & Numerator parameter-dependent regressors. & - \\
\hline$a_{j}(\rho)$ & Denominator parameter-dependent regressors. & - \\
\hline$\beta_{j}^{k}$ & Numerator regressors polynomial coefficients. & - \\
\hline$\alpha_{j}^{k}$ & Denominator regressors polynomial coefficients. & - \\
\hline$m_{j}$ & Slope coefficient of piecewise F-V equation. & - \\
\hline$c_{j}$ & Offset coefficient of piecewise F-V equation. & \\
\hline$\mu_{j}$ & Velocity limits Regressor coefficient & - \\
\hline$\sigma_{j}$ & Electric current-dependent scale factor. & - \\
\hline$\psi_{j}$ & Electric current-dependent correction factor. & in/sec \\
\hline$\gamma_{j}$ & Regressor of slope/intercept constants. & - \\
\hline & & \\
\hline
\end{tabular}

Equation (2) is a second-order nonlinear ordinary relationship. Parameters $F_{m r}(t), F_{m r}^{3}(t)$, and $F_{m r}^{5}(t)$ are used to represent the hysteresis of the MR damper, by recreating the phase transition of the MR fluid in the one-dimension. Parameters $\dot{F}_{m r}(t)$ and $\ddot{F}_{m r}(t)$ in the model, are used to capture the dynamics of the phase switching.

According to [7], all coefficients $\left(w_{j}\right)$ should be identified using experimental data. These coefficients are assumed to be a polynomial function of the magnetic field in order to achieve a more general model.

\section{LPV-BASED SYSTEM}

MR damper complex behavior can also be described by the use of a Linear-Parameter-Varying (LPV) model. They belong to the set of Linear Time-Varying Systems, and are described in a finite dimension space. Their state-space representation is given by the weighted sum of local state vectors, such as the time dependency is hidden among these parameters.

$$
\left[\begin{array}{l}
\dot{\mathbf{z}}(t) \\
f(t)
\end{array}\right]=\left[\begin{array}{ll}
A(\rho(t)) & B(\rho(t)) \\
C(\rho(t)) & D(\rho(t))
\end{array}\right]\left[\begin{array}{l}
\mathbf{z}(t) \\
u(t)
\end{array}\right]
$$

The $\rho(t)$-parameter modifies the behavior of the system; it is delimited by a finite space:

$$
\rho \in U_{\rho} \subset \mathfrak{R}^{\lambda} \text {, and } U_{\rho} \text { compact }
$$

where the relationship is valid only if $U_{\rho}$ is bounded.

The importance of this model lies in the ability to change its dynamics over time. The pointer variable $(\rho(t))$ changes the states according to a variable of scheduling, whose selection is essential for the a good modeling of the device.

Matrices dependency of the scheduling variable is proposed by means of a polynomial linear system [11], [12]:

$$
\begin{aligned}
& {\left[\begin{array}{ll}
A(\rho(t)) & B(\rho(t)) \\
C(\rho(t)) & D(\rho(t))
\end{array}\right]=\left[\begin{array}{ll}
A_{0} & B_{0} \\
C_{0} & D_{0}
\end{array}\right]+\sum_{i=1}^{N} \rho^{\delta_{i}}(t)\left[\begin{array}{ll}
A_{i} & E_{i} \\
C_{i} & F_{i}
\end{array}\right]} \\
& \rho(t) \in\left[\rho_{\min }, \rho_{\max }\right]
\end{aligned}
$$

It is important, to ensure that the system based on $\rho$ scheduling parameter is stable within a specific region.

\section{A. LPV-based model proposal}

The continuous LPV-based model (equation (3)) can be represented with a discrete-time transfer function:

$$
G(z, \rho)=\frac{N(z, \rho)}{M(z, \rho)}
$$

where numerator and denominator depend on the $\rho$ scheduling parameter. $N(z, \rho)$, and $M(z, \rho)$ can be defined as:

$$
\begin{aligned}
N(z, \rho) & =b_{0}(\rho)+b_{1}(\rho) z^{-1}+\ldots+b_{n_{m}}(\rho) z^{-n_{m}} \\
M(z, \rho) & =1+a_{1}(\rho) z^{-1}+a_{2}(\rho) z^{-2}+\ldots+a_{n_{m}}(\rho) z^{-n_{m}}
\end{aligned}
$$

Similarly its coefficients can be approximated by:

$$
\begin{aligned}
& b_{i}(\rho)=\beta_{i}^{0}+\beta_{i}^{1} \cdot \rho^{1}(k)+\beta_{i}^{2} \cdot \rho^{2}(k)+\ldots+b_{i}^{n_{\rho}} \cdot \rho^{n_{\rho}}(k) \\
& a_{i}(\rho)=\alpha_{i}^{0}+\alpha_{i}^{1} \cdot \rho^{1}(k)+\alpha_{i}^{2} \cdot \rho^{2}(k)+\ldots+\alpha_{i}^{n_{\rho}} \cdot \rho^{n_{\rho}}(k)
\end{aligned}
$$

This discrete-time approximation can be expressed in a state space model. The controllable canonical state space representation of equations (7-9) is:

$$
\begin{aligned}
& \mathbf{z}(k+1)=A(\rho) \mathbf{z}(k)+B(\rho) u(k) \\
& \mathbf{z}(k+1)=\left[\begin{array}{ccccc}
0 & 1 & 0 & \ldots & 0 \\
0 & 0 & 1 & \cdots & 0 \\
\vdots & \vdots & \vdots & \ddots & \vdots \\
0 & 0 & 0 & \cdots & 1 \\
-a_{m}(\rho) & -a_{m-1}(\rho) & -a_{m-2}(\rho) & \cdots & -a_{1}(\rho)
\end{array}\right] \cdot \mathbf{z}(k)+\left[\begin{array}{c}
0 \\
0 \\
0 \\
\vdots \\
1
\end{array}\right] u(k)
\end{aligned}
$$

and the output:

$$
\begin{aligned}
f(k)= & C(\rho) x(k)+D(\rho) u(k) \\
f(k)= & {\left[\left(b_{n}(\rho)-a_{n}(\rho) \cdot b_{0}(\rho)\right)\left(b_{n-1}(\rho)-a_{n-1}(\rho) \cdot b_{0}(\rho)\right) \quad \ldots\right.} \\
& \left.\quad\left(b_{1}(\rho)-a_{1}(\rho) \cdot b_{0}(\rho)\right)\right] \mathrm{x}(\mathrm{k})+b_{0}(\rho) \cdot u(k)
\end{aligned}
$$


which clearly agrees with the LPV system description of equation (6). When including the $\rho$ functionality (8), the model matrices become:

$$
\begin{aligned}
A(\rho(k))= & {\left[\begin{array}{cccc}
1 & 0 & \ldots & 0 \\
0 & 1 & \ldots & 0 \\
\vdots & \vdots & \ddots & \vdots \\
-\alpha_{n a}^{0}-\alpha_{n a-1}^{0} & \ldots & -\alpha_{1}^{0}
\end{array}\right]+\left[\begin{array}{cccc}
0 & 0 & \ldots & 0 \\
0 & 0 & \ldots & 0 \\
\vdots & \vdots & \ddots & \vdots \\
-\alpha_{n a}^{1}-\alpha_{n a-1}^{1} & \ldots & -\alpha_{1}^{1}
\end{array}\right] \rho(k)+\ldots } \\
+ & {\left[\begin{array}{cccc}
0 & 0 & \ldots & 0 \\
0 & 0 & \ldots & 0 \\
\vdots & \vdots & \ddots & \vdots \\
-\alpha_{n a}^{N p} & -\alpha_{n a-1}^{N p} & \ldots & -\alpha_{1}^{N \rho}
\end{array}\right] \cdot \rho^{N \rho}(k) } \\
& B^{T}(\rho(k))=\left[\begin{array}{lllll}
0 & 0 & 0 & \ldots & 1
\end{array}\right]
\end{aligned}
$$

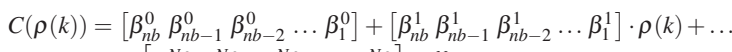
$+\left[\beta_{n b}^{N \rho} \beta_{n b-1}^{N \rho} \beta_{n b-2}^{N \rho} \ldots \beta_{1}^{N \rho}\right] \cdot \rho^{N \rho}(k)$

$$
D(\rho(t))=0
$$

$b_{0}(\rho)=0$, is assumed.

\section{B. Scheduling parameter}

The scheduling parameter is of great importance in the $L P V$-based model formulation. The scheduling parameter will be designed as the electric current input based on Figure 1.

$$
\rho(k)=i(k), \quad \forall i(k) \in\left[0, i_{\max }\right]
$$

\section{Slope and Intercept analysis}

A clear functionality between the force and velocity signals can be appreciated in Figure 2, where a static forcevelocity map is shown. A piecewise straight-line regression (17) was plotted in this graph based on:

$F(v(t))=\left\{\begin{array}{lll}m_{1} \cdot v(k)+c_{1} & \text { if } \quad v(k)<v_{\text {low }} & \text { (Zone I) } \\ m_{2} \cdot v(k)+c_{2} & \text { if } v_{\text {low }} \leq v(k) \leq v_{\text {high }} & \text { (Zone II) } \\ m_{3} \cdot v(k)+c_{3} & \text { if } \quad v(k)>v_{\text {high }} & \text { (Zone III) }\end{array}\right.$

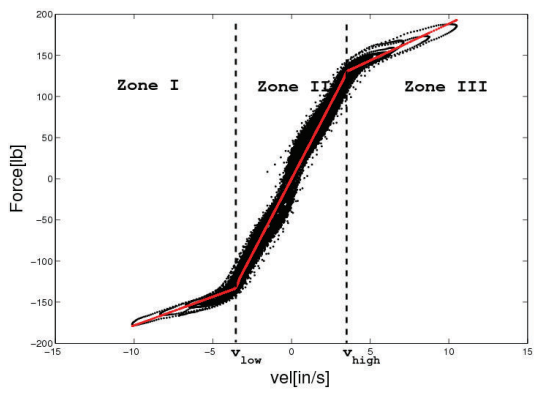

Fig. 2. Measured and straight-line regression for the force-velocity map for an electric current input of 1.2 Amps.

For each zone in Figure 2, a $m_{j}$-slope and $c_{j}$-intercept were computed, see Figure 3. As the electric current grows up, the slope becomes greater.

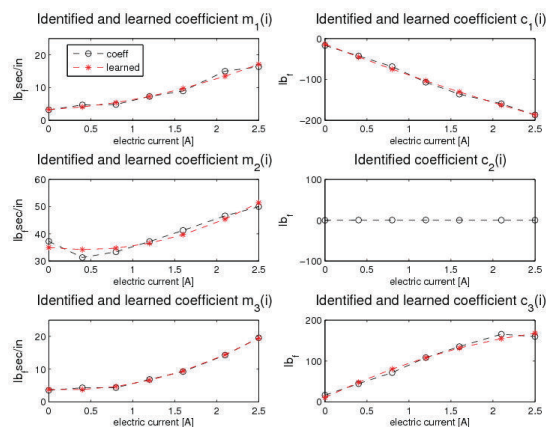

Fig. 3. Identified m-slope and c-intercept coefficients and fitted regression curves.

(14) Slope and intercept coefficients depend on the following electric current equations: $m(i)=\gamma_{m_{2}} \cdot i^{2}+\gamma_{m_{1}} \cdot i+\gamma_{m_{0}}$, and $c(i)=\gamma_{c_{2}} \cdot i^{2}+\gamma_{c_{1}} \cdot i+\gamma_{c_{0}}$.

\section{Input signal and hysteresis replication.}

In order to aid the LPV model to describe the force hysteresis, an input variable is proposed. This signal will detect when the MR damper is exploring an hysteretic zone. The definition of this variable is based on the following analysis.

The MR damper output force is clearly related to the displacement velocity of the piston, Figure 4 . This relationship shows hysteretic zones in the force-velocity static map.

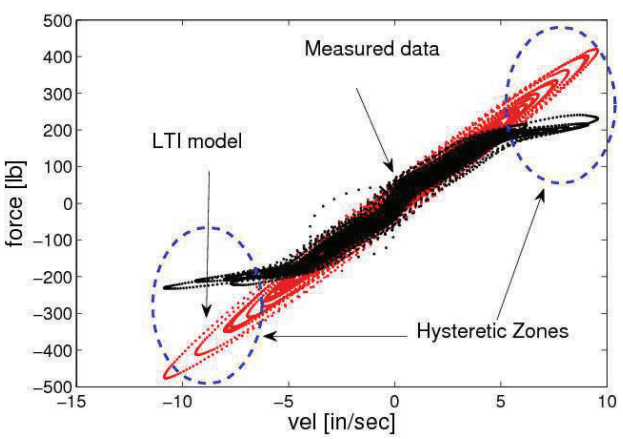

Fig. 4. Model output results when modeling the MR damper using an LTI system. Experiment 8 (1.2 Amp).

It is clear that the force-velocity map changes when the velocity surpasses or fall behind some velocity limits. These limits are symmetric $v_{\text {high }}=-v_{\text {low }}$. Also, these limits change with electric current input.

Velocity limits linearly depend on the electric current.

$$
v_{\text {high }}(i)=\left|v_{\text {low }}(i)\right|=\mu_{1} \cdot i+\mu_{2}
$$

The relevance of these limits lies in the fact that the $L P V$ based model should detect when the velocity changes from zone to zone in the force-velocity map, even if the electric current is changing at the same time. 


\section{E. Input variable definition}

A new input variable will be computed based on the above observations, such as it detects when the damper is exploring an hysteretic region, and takes into account the force-velocity slope change to aid the LPV model to remain attached to the MR damper force.

LPV input variable $u(t)$ is closely related to the velocity $v(t)$. The main purpose of this variable is to provide a saturation on the velocity measures when they reach magnitudes above the velocity limits defined previously. This relationship is proposed as:

$$
\begin{array}{r}
u(k)=f(v(k), i(k))=\sigma(i(k)) \cdot v(k)+\psi(i(k)), \quad \text { and } \\
|u(k)| \leq|v(k)|, \quad \forall k
\end{array}
$$

where $\sigma(i(t))$ is a scale factor for the velocity, that will reduce the velocity magnitude when it exceeds its border limit and $\psi(\mathrm{i}(\mathrm{t}))$ is the correction factor used to ensure the variable continuity near the scale changes.

$$
\sigma(i(k)) \in[0,1], \quad|\psi(i(k))|<|v(k)|
$$

These scale and correction factor are experimentally computed; then both factors are normalized with the central slope $m_{2}(i(t))$, which is always the biggest slope value. This normalization is done in order to maintain the force-velocity relationship untouched when using the same LTI model to represent the three different zones of the force-velocity static plane.

The switching variable that will guide the $L P V$-based model to follow hysteretic patterns, can be computed as:

$$
\begin{gathered}
u(k)=f(v(k), i(k))=\sigma(i(k)) \cdot v(k)+\psi(i(k)) ; \\
u(k)= \begin{cases}\frac{m_{1}(i(k))}{m_{2}(i(k))} \cdot v(k)+\frac{c_{1}(i(t))}{m_{2}(i(k))} & \text { if } v(t)>v_{\text {high }}(i(t)) \\
v(k) & \text { if } v_{\text {low }}(i(k)) \leq v(k) \leq v_{\text {high }}(i(k)) \\
\frac{m_{3}(i(k))}{m_{2}(i(k))} \cdot v(k)+\frac{c_{3}(i(k))}{m_{2}(i(k))} & \text { if } v(k)<v_{\text {low }}(i(k))\end{cases}
\end{gathered}
$$

\section{EXPERIMENTAL SySTEM}

The experimental system contains three main components: actuators (displacement and electric current), data acquisition (DAQ) devices, and a control system, Figure 5. The data acquisition system Flextest ${ }^{\mathrm{TM}}$ commands the controller and records the position and force from the MR damper.

The hydraulic servo-controlled piston introduces a displacement excitation sequence $\left(x_{i n}\right)$ commanded by the DAQ system $\left(x_{u}\right)$, and measured in the LVDT sensor $\left(x_{m s}\right)$. The MR damper force $\left(F_{M R}\right)$ is measured by means of a load cell located at the union of the damper and the piston. The electric current excitation is introduced into the damper and is measured by an electric current transducer. Measured signals are monitored through HMI. The displacement and

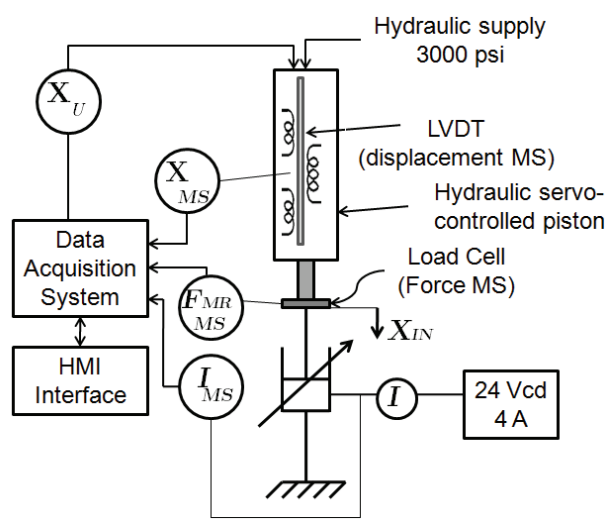

Fig. 5. Experimental system.

electric current range are: 0 - $0.04 \mathrm{~m}$, and 0 - 4 A respectively. The measured span of the MR damping force is $0-2850 \mathrm{~N}$.

Eight training sequences were designed to obtain the data for the learning process. Each sequence considers both a displacement and electric current patterns. For each training sequence, various replicates were done, Table V.

The first 1-5 training sequences contain recurrent signals (changing in time) for the electric current pattern. These sequences generate a useful database for the training of electric current dependent models. Experiments 6-8 contain Stepped InCrements (SC) in the electric current sequence; by using these experiments it was possible to appreciate the dependency of the current in the force-velocity map of the MR damper.

TABLE II

Design of Experiments (DoE) Training SEQuences.

\begin{tabular}{|c|c|c|c|c|c|}
\hline \hline Exp & $\begin{array}{c}\text { Displacement } \\
\text { pattern }\end{array}$ & $\begin{array}{c}\text { Current } \\
\text { pattern }\end{array}$ & $\begin{array}{c}\text { Duration } \\
\text { (sec.) }\end{array}$ & $\begin{array}{c}\text { No. of } \\
\text { replicates }\end{array}$ & $\begin{array}{c}\text { Max. Freq. } \\
\text { Value (Hz) }\end{array}$ \\
\hline \hline 1 & Road Profile & ICPS & 30 & 11 & 5.5 \\
2 & Road Profile & APRBS & 30 & 11 & 4.5 \\
3 & Road Profile & PRBS & 30 & 11 & 4.2 \\
4 & Long Road Profile & APRBS & 600 & 3 & 4.5 \\
5 & Long Road Profile & ICPS & 600 & 4 & 5.5 \\
6 & Road Profile & SC & 30 & 7 & 5.5 \\
7 & Road Profile & SC & 30 & 7 & 4.5 \\
8 & Road Profile & SC & 30 & 7 & 4.5 \\
\hline \hline
\end{tabular}

A comparison of the models was done based on two performance indices. Squared root of Sum of Squared Errors (SSSE) index, which is the squared root of a $L_{2}$ norm of the fitting error of the learned MR damper models, normalized by the number of samples of the test. Error to Signal Ratio (ESR) index is a similar index, but it is divided by the MR damper force variance. These indices are computed as follows:

$$
\begin{gathered}
S S S E=\sqrt{\frac{1}{n_{s}} \sum_{t=1}^{n_{s}}(F(t)-\hat{F}(t))^{2}} \\
E S R=\frac{\frac{1}{n_{s}} \sum_{t=1}^{n_{s}}(F(t)-\hat{F}(t))^{2}}{\frac{1}{n_{s}} \sum_{t=1}^{n_{s}}\left(F(t)-\left(\frac{1}{n_{s}} \sum_{i=1}^{n_{s}} F(i)\right)\right)^{2}}
\end{gathered}
$$



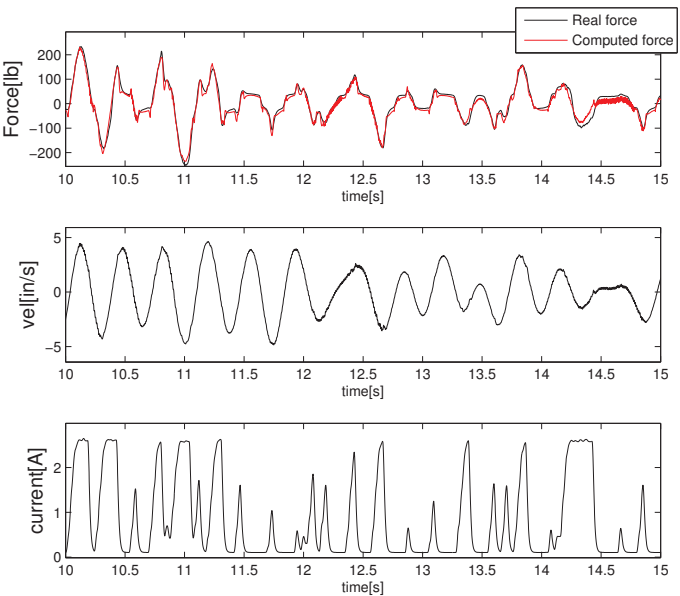

Fig. 6. Experimental Data. Top plot represents the real and computed damper force ( $L P V$-based model). Middle plot shows piston velocity and bottom plot presents the electric current applied to the MR damper.

\section{RESULTS}

Six different models were validated in order to include the electric current, a polynomial approximation was used. For the case of the $P$ model [7], a second order polynomial was applied to all its coefficients. For the $S P$ model, four different modifications were tested, focusing mainly on the hyperbolic term of the equation. The modified models are shown:

\begin{tabular}{c|c} 
Name & Equation \\
\hline P-15 & $F_{m r}=w_{1}(i) v+w_{2}(i) \dot{F}+w_{3}(i) \ddot{F}+w_{4}(i) F^{3}+w_{5}(i) F^{5}$ \\
SP-1 & $F_{m r}=S_{1}(i) \cdot \tanh \left(S_{2}(i) v+S_{3}(i) x\right)+S_{4}(i) v+S_{5}(i) x$ \\
SP-2 & $F_{m r}=S_{1} \cdot i \cdot \tanh \left(S_{2} v+S_{3} x\right)+S_{4} v+S_{5} x$ \\
SP-3 & $F_{m r}=\left(S_{1} \cdot i+S_{2}\right) \cdot \tanh \left(S_{3} v+S_{4} x\right)+S_{5} v+S_{6} x$ \\
SP-4 & $F_{m r}=\left(S_{1} i^{2}+S_{2} i+S_{3}\right) \cdot \tanh \left(S_{4} v+S_{5} x\right)+S_{6} v+S_{7} x$
\end{tabular}

These models were identified, using a least-squares algorithm [11]. Figure 6 shows an example of modeling results for the $L P V$-based model. As it can be seen, velocity and electric current change during the experiment, while the modeled force remains close to the experimental force.

\section{A. ESR results comparison.}

Figure 7 shows a box and whiskers plot for the ESR index of each model. The boxes have lines at the lower, median, and upper quartile values. The whiskers show the extent of the rest of the data. Outliers are data with values beyond the ends of the whiskers. It is shown that for the case of the $P$ and $S P-1$ models, the results are very similar. It can be noted, that for the $S P-2, S P-3$ and $S P-4$ models, there is no reduction even when changing the amount of coefficients. Finally, the LPV-based model outperforms all the models. The $E S R$ average achieved for the $L P V$-based model (0.036) is $51 \%$ below the best results of the other models ( $S P-1$, $0.074)$.

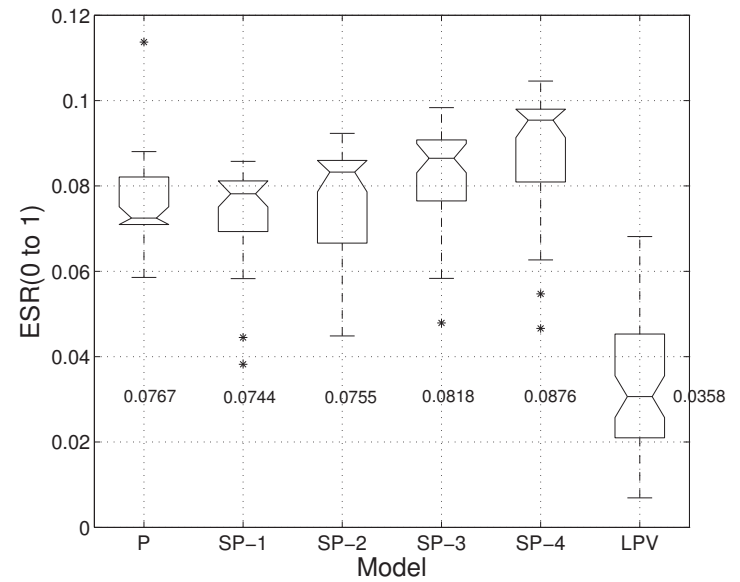

Fig. 7. ESR index results. Comparison of models. ESR average is shown below the box for every model

\section{B. SSSE results comparison.}

The statistics results based on Squared-root of SSE (SSSE) for each equation are shown in Figure 8 . The pattern results are similar: $L P V$-based model outperforms other models. The SSSE average for the $L P V$-based model is 14.98 , which represents an improvement of $36.8 \%$ w.r.t. $S P-1$ model, which is the second SSSE best with an average of 23.72 .

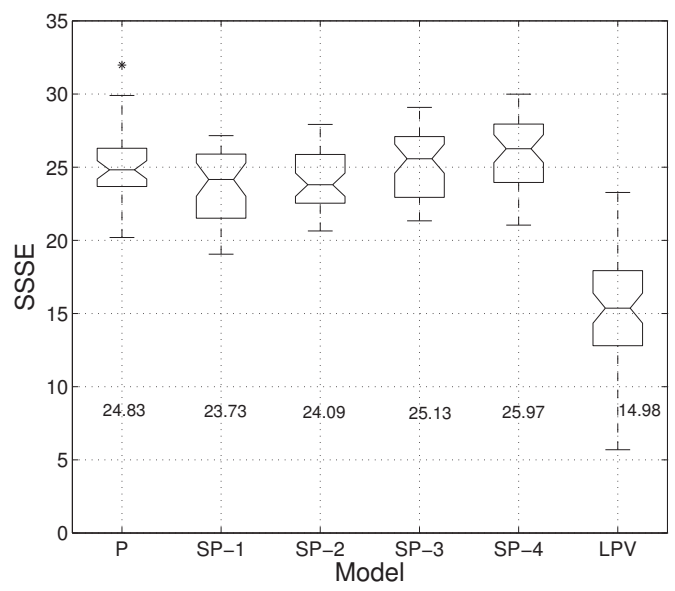

Fig. 8. SSSE index results. Comparison of different models. SSSE average is shown below the box for every model 


\section{Discussion}

In the force-time comparison between the models, the best structures are in order of importance the $L P V$-based, $P$ and $S P-1$ structures, see Figure 9 . In the force-velocity static plane, the best models are the $L P V$-based and $P$ models, see Figure 10.

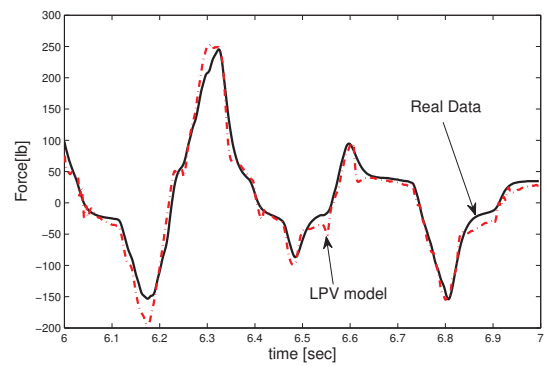

Fig. 9. Real and Computed Damper Force.

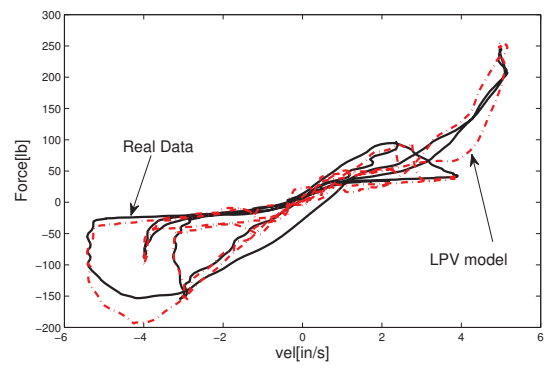

Fig. 10. F-V static map. Comparison real and computed data.

In [9], [13]-[15] an $L P V$ model structure for the quarter of vehicle is proposed, by the use of a static relationship to handle the non-linear relationship of the damper. Based on this model, a control scheme was designed to regulate the vibrations received by the wheels of the car, and assure, in this way, the vehicle safety, improving at the same time the comfort of the passengers.

The LPV-based model proposed only recreates the dynamic behavior of the damper. It represents an innovative way to represent this non-linear system, and it might be extended to handle the whole suspension system, suitable for control design. This represents a great improvement in the performance of these type of controllers.

\section{CONCLUSIONS}

MR Dampers represent a key component in the field of intelligent suspensions; because, they can easily improve the comfort and handling control systems. However, these devices exhibit a high nonlinear and complex behavior with an hysteresis phenomenon that represent a modeling challenge. Several classical models were learned, exploiting experimental datasets taken from an industrial MR Damper. A new structure of Linear Parameter Varying ( $L P V)$-based model with an electrical current variable is presented. Based on both ESR and SSSE indices, the LPV-based model outperforms the Phenomenological $(P)$, and Semi-Phenomenological $(S P)$ models. Furthermore, some modifications considering the electrical current variable were implemented; $L P V$-based model is $51 \%$ better than any structures considering the ESR index, and $37 \%$ better considering the SSSE index. Also, $L P V$-based model shows a compact and simple equation, suitable for control design.

\section{AKNOWLEDGEMENTS}

Special thanks to Dr. Olivier Sename and Dr. Luc Dugard for the opportunity given in the research stay at GIPSA Lab, and to CONACYT for the economic funding which made possible this research.

\section{REFERENCES}

[1] B.F. Spencer, S.J. Dyke, M.K. Sain, and J.D. Carlson. Phenomenological Model of a MR Damper. ASCE J. of Eng. Mechanics, 1996.

[2] S.M. Savaresi, S. Bittanti, and M. Montiglio. Identification of SemiPhysical and Black-box Non-Linear Models: the case of MR-Dampers for vehicles Control. Automatica, 41(1):113-127, 12005.

[3] N. M. Kwok, Q. P. Ha, M. T. Nguyen, J. Li, and B. Samali. BoucWen Model Parameter Identification for a MR Fluid Damper using Computationally Efficient GA. ISA Trans, 46(2):167-179, 42007.

[4] P.Y. Lin, P. Roschke, and C. H. Loh. System Identification and Real Application of the Smart Magneto-Rheological Damper. In Proc. of the 2005 IEEE Int Symp. on, Mediterrean Conf. on Control and Automation, pages 989-994, 2005.

[5] J. Ruiz-Cabrera, V. Diaz-Salas, R. Morales-Menendez, L. GarzaCastanon, and R. Ramirez-Mendoza. Comparison of MR damper models. In Control Automation (MED), 2010 18th Mediterranean Conference on, pages $1509-1513,2010$.

[6] S. Guo, S. Li, and S. Yang. Semi-Active Vehicle Suspension Systems with Magnetorheological Dampers. In Vehicular Electronics and Safety, 2006. IEEE Int. Conf. on, pages 403-406, 2006.

[7] L.X. Wang and H. Kamath. Modelling Hysteretic Behaviour in MR Fluids and Dampers using Phase-Transition Theory. Smart Mater. Struct., 15:1725-1733, 2006.

[8] E. Nino-Juarez, R. Morales-Menendez, R. Ramírez-Mendoza, and L. Dugard. Minimizing the Frecuency in a Black Box Model of a Magneto-Rheological Damper. In 11 Mini Conf. on Vehicle Sys. Dyn., Ident. and Anomalies, pages 36-36, 2008.

[9] D. Anh-Lam, O. Sename, and L. Dugard. An LPV Control Approach for Semi-active Suspension Control with Actuator Constraints. In American Control Conf., pages 4653 - 4658, 2010.

[10] L. Dugard O. Sename R. Ramírez-Mendoza R. Morales-Menendez. Do Anh-Lam, J. Lozoya-Santos. Modélisation et Commande LPV d'un amortisseur MR. In $6^{\circ}$. IEEE Conf. Int Francophone d'Automatique., 2010.

[11] B. Bamieh and L. Giarré. Identification of Linear Parameter Varying Models. Int. J. of Robust and Nonlinear Control, 12(9):841-853, 2 2002.

[12] B. Bamieh, L. Giarré, T. Raimondi, D. Bauso, M. Lodato, and D. Rosa LPV Model Identification for the Stall and Surge Control of Jet Engine. In $15^{\text {th }}$ IFAC Symp. on Automatic Control in Aerospace, pages 156-161, 2001.

[13] C. Poussot-Vassal, O. Sename, L. Dugard, P. Gspr, Z. Szab, and J. Bokor. A New Semi-Active Suspension Control Strategy through LPV technique. Control Engineering Practice, 2008.

[14] M. Meisami-Azad, J. Mohammadpour, and K. M. Grigoriadis. AntiWindup LPV Control of Magneto-Rheological Dampers. ASME Conf. Proc., 2009:817-824, 2009.

[15] J. J. Lozoya-Santos, R. Morales-Menendez, and R. Ramírez-Mendoza IMC of a MR Damper. $10^{\circ}$ European Control Conference, August 2009. 